Article

\title{
Fabrication and Characterization of Graphene Microcrystal Prepared from Lignin Refined from Sugarcane Bagasse
}

\author{
Pei-Duo Tang ${ }^{1}$, Qi-Shi Du ${ }^{1,2, *(1)}$, Da-Peng $\mathrm{Li}^{3}{ }^{3}$ Jun Dai ${ }^{1}$, Yan-Ming $\mathrm{Li}^{1}{ }^{1}$, Fang-Li Du ${ }^{1}$, \\ Si-Yu Long ${ }^{1}$, Neng-Zhong Xie ${ }^{1}$, Qing-Yan Wang ${ }^{1}$ and Ri-Bo Huang ${ }^{1, *}$ \\ 1 State key Laboratory of Bioenergy Enzyme Technology, National Engineering Research Center for Non-Food \\ Biorefinery, Guangxi Academy of Sciences, Nanning 530007, China; tangpeiduo@gxas.cn (P.-D.T.); \\ 18577113352@126.com (J.D.); lym810555@163.com (Y.-M.L.); dfl@gxas.cn (F.-L.D.); \\ xbslongsiyu@163.com (S.-Y.L.); xienengzhong@gxas.cn (N.-Z.X.); qingyanw@126.com (Q.-Y.W.) \\ 2 Gordon Life Science Institute, 53 South Cottage Road, Belmont, MA 02478, USA \\ 3 Institute of Surface Micro and Nano Materials, Xuchang University, Xuchang 461000, China; \\ lidapengabc@126.com \\ * Correspondence: duqishi@foxmail.com (Q.-S.D.); rbhuang@gxas.ac.cn (R.-B.H.); \\ Tel.: +86-771-250-3931 (Q.-S.D.); Tel.: +86-771-250-3970 (R.-B.H.)
}

Received: 23 June 2018; Accepted: 19 July 2018; Published: 24 July 2018

\begin{abstract}
Graphene microcrystal (GMC) is a type of glassy carbon fabricated from lignin, in which the microcrystals of graphene are chemically bonded by $\mathrm{sp}^{3}$ carbon atoms, forming a glass-like microcrystal structure. The lignin is refined from sugarcane bagasse using an ethanol-based organosolv technique which is used for the fabrication of GMC by two technical schemes: The pyrolysis reaction of lignin in a tubular furnace at atmospheric pressure; and the hydrothermal carbonization (HTC) of lignin at lower temperature, followed by pyrolysis at higher temperature. The existence of graphene nanofragments in GMC is proven by Raman spectra and XRD patterns; the ratio of $\mathrm{sp}^{2}$ carbon atoms to $\mathrm{sp}^{3}$ carbon atoms is demonstrated by XPS spectra; and the microcrystal structure is observed in the high-resolution transmission electron microscope (HRTEM) images. Temperature and pressure have an important impact on the quality of GMC samples. With the elevation of temperature, the fraction of carbon increases, while the fraction of oxygen decreases, and the ratio of $\mathrm{sp}^{2}$ to $\mathrm{sp}^{3}$ carbon atoms increases. In contrast to the pyrolysis techniques, the HTC technique needs lower temperatures because of the high vapor pressure of water. In general, with the help of biorefinery, the biomass material, lignin, is found to be qualified and sustainable material for the manufacture of GMC. Lignin acts as a renewable substitute for the traditional raw materials of glassy carbon, copolymer resins of phenol formaldehyde, and furfuryl alcohol-phenol.
\end{abstract}

Keywords: graphene microcrystal; glassy carbon; lignin; bagasse; biorefinery; graphene; biomass

\section{Introduction}

Glassy carbon, or vitreous carbon, is a non-graphitizing and crystallized carbon, which combines glassy and ceramic properties with those of graphite, but cannot be graphitized at any temperature [1-3]. Glassy carbon is not amorphous matter, but has a glass-like microcrystal structure, consisting of microcrystals of fullerene, carbon nanotube, and/or graphene [1-3]. In the microstructure of glassy carbon materials, the $\mathrm{sp}^{2}$ carbon atoms are chemically bonded by $\mathrm{sp}^{3}$ carbon atoms, forming a 3D structural network [4-9]. The possession of such a unique structure grants glassy carbon a great variety of physical and chemical properties [10-14]. The most important properties of glassy carbon are high hardness, low density, high temperature resistance, low electrical and thermal resistance, 
low friction, extreme impermeability to gases and liquids at very high temperatures, and resistance to chemical attack [10,15-17]. Glassy carbon materials are widely used in many extreme fields because of their unique and excellent properties.

Typically, glassy carbon is manufactured in an inert gaseous atmosphere by heat treatment at elevated temperatures $\left(1000-2400^{\circ} \mathrm{C}\right.$ ) from organic polymeric precursors, such as copolymer resins of phenol formaldehyde or furfuryl alcohol-phenol $[8,18,19]$. These polymers are used because of their high carbon yield upon pyrolysis, in which the increase in the proportion of carbon after carbonization is around $\sim 50 \%$ compared to before [20]. Although glassy carbon was first discovered in the 1960s [1,21], the fabrication methods of glassy carbon have been continuously improved upon. Theoretical study on the structure of glassy carbon has also steadily progressed since its discovery. In recent years, the newly invented fullerene, carbon nanotube, and graphene helped researchers to restudy and re-evaluate the microstructures of glassy carbon [7,8,22,23]. Graphene, particularly, has obtained extended uses in drug delivery, membrane, biomedical and adsorption applications, in addition to use in sensors [24-28].

In a recent study, it was found that by adding a small fraction of carbon nanotubes to a phenol-formaldehyde polymer, similar glassy carbon could be achieved at $800{ }^{\circ} \mathrm{C}, 200{ }^{\circ} \mathrm{C}$ lower than the previous temperature [7]. Another study reported that compression of glassy carbon at high pressure and certain temperatures induced the local buckling of graphene sheets through $\mathrm{sp}^{3}$ nodes to form interpenetrating graphene networks with a long-range disorder and short-range order on a nanometer scale [10]. Such compressed glassy carbons have extraordinary specific compressive strengths - more than two times that of commonly used ceramics - and simultaneously exhibit robust elastic recovery in response to local deformations [10]. A study reported that in the fabrication of glassy carbon, the traditional raw materials, phenol formaldehyde or furfuryl alcohol-phenol, were successfully replaced by camphor, a natural and renewable source [29].

The traditional precursors of glassy carbon are produced from coal, petroleum, or natural gas $[3,4,19,30]$. The over-consumption of fossil materials has caused global warming, frequent occurrences of extreme weather, and ecological disaster [31,32]. To deal with the global environmental and ecological problems, biomass (particularly the waste from the agriculture and forest industries), is the best way to replace coal, petroleum, and natural gas as both the energy fuel and raw materials of the chemical and material industries [33-38]. Lignin is the second largest renewable biomass material in the natural world and has been used in the fabrication of graphene by several authors [39,40]. In this study, the green and sustainable biomass material, lignin, is used to prepare the graphene microcrystal, a type of glassy carbon, in which the nanoscale graphene fragments are chemically bonded by $\mathrm{sp}^{3}$ carbon atoms. In this study, such glassy carbon is named graphene microcrystal (GMC), to differentiate it from other types of glassy carbon $[1-3,6,9]$.

\section{Experimental Section}

Not all commercially available lignin products are good materials for the fabrication of GMC. The Kraft lignin [41], is a sulfate lignin, i.e., lignin containing sulfur, which is not suitable for the fabrication of GMC. In this study, the precursor lignin is refined, using an organosolv technique, from sugarcane bagasse, which is a pure lignin polymer, consisting solely of carbon, oxygen, and hydrogen.

\subsection{Biorefinery of Sugarcane Bagasse}

The fresh sugarcane bagasse used in this study is provided by a cane mill of Nanning sugar industry CO., LTD (http://www.nnsugar.com/) in Guangxi, China. The main components in sugarcane bagasse are comprehensively analyzed, and the general results are as follows: Cellulose $45-55 \%$, hemicellulose 20-25\%, lignin 18-24\%, ash 1-4\%, and waxes $<1 \%$, which are consistent with the reference [42]. 
The ethanol-based organosolv technique, developed by Guangxi Botanical Institute (http:/ / www.gxib.cn/), is used for the biorefinery of bagasse. The bagasse is ground to a 40 mesh $(0.45 \mathrm{~mm})$ powder, followed by drying in a loft drier for $2 \mathrm{~h}$ at $120^{\circ} \mathrm{C}$. The bagasse powder is then soaked in a $55 \mathrm{wt} \%$ ethanol-water solution in $\mathrm{pH}=3.0 \sim 4.0$ conditions, followed by heating to $200{ }^{\circ} \mathrm{C}$ for $100 \mathrm{~min}$ in a specially designed boiler. In this process, the chemical bonds between lignin and cellulose/hemicellulose are broken, and lignin dissolves in the ethanol-water solution. The undissolved cellulose and hemicellulose are removed from the solution to a reactor, where the hemicellulose is hydrolyzed to xylose at $140{ }^{\circ} \mathrm{C}$ for $20 \mathrm{~min}$ in acidic conditions, after which it is separated with cellulose. The dissolved lignin in the ethanol-water solution is recovered by solvent vaporization. Unlike Kraft lignin $[43,44]$, refined lignin has the same structure as pure lignin, consisting of only carbon, oxygen and hydrogen elements, with no other heteroatoms, such as sulfur, nitrogen, and sodium. The technical scheme of the biorefinery is illustrated in Figure 1.

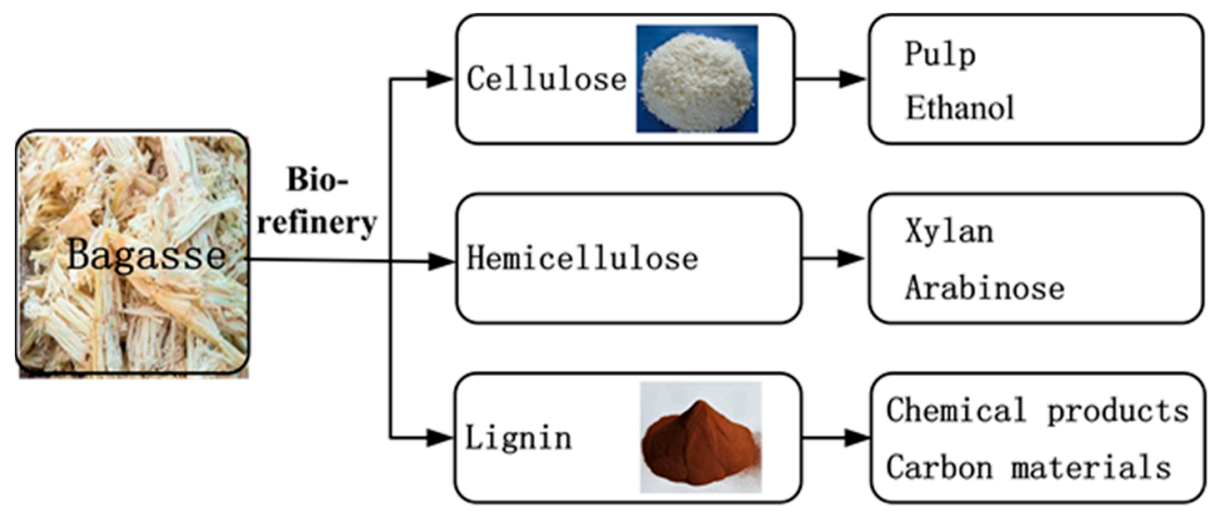

Figure 1. The sugarcane bagasse is refined into cellulose, hemicellulose, and lignin using an ethanol-based organosolv technique. The cellulose is used for the production of pulp and ethanol fuel, the hemicellulose is used for the medicinal and nutritional product xylan, and the lignin is used for the fabrication of graphene microcrystals (GMC) described in this study.

\subsection{Structure of Lignin}

The chemical composition of lignin is shown in Figure 2, where (a) is the structural fragment of lignin polymer; and (b) shows the chemical structures of three composition monomers of lignin: $p$-Coumaryl alcohol, coniferyl alcohol, and sinapyl alcohol, respectively $[45,46]$. The chemical structure of lignin, shown in Figure 2a, is an approximate description, as the composition of lignin varies from species to species. Lignin has the most abundant carbon component among all natural organic polymers, in which the element composition is around $63.4 \%$ carbon, $30 \%$ oxygen, 5.9\% hydrogen, and $0.7 \%$ ash (mineral components) [47], corresponding, approximately, to the formula $\left(\mathrm{C}_{31} \mathrm{H}_{34} \mathrm{O}_{11}\right) \mathrm{n}$. In lignin, the carbon element is higher than that in the traditional precursor of glassy carbon, phenol formaldehyde, and furfuryl alcohol-phenol. Particularly, lignin contains both $\mathrm{sp}^{2}$ and $\mathrm{sp}^{3}$ carbon atoms at a ratio of approximately 33:12, which is very favorable for the composition of glassy carbon [10,48]. Lignin is, in fact, the precursor of phenol formaldehyde and furfuryl alcohol-phenol $[46,49]$, the traditional raw materials of glassy carbon.

Figure 3 shows the SEM images of lignin particles obtained from an ethanol-water solution by evaporation of the solvent. Most lignin particles are rough spheres with a diameter of tens to hundreds of micrometers. Some of the lignin particles may be hollow spheres or pieces of broken spheres. 


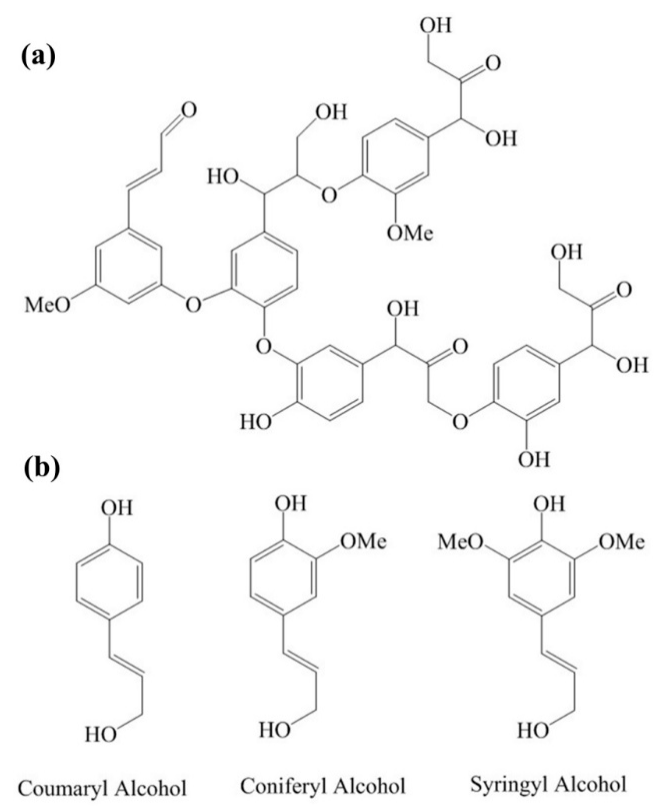

Figure 2. The chemical structure and composition of lignin. (a) Structural fragment of a lignin polymer. Lignin is a series of randomly cross-linked phenolic polymers. It has no specific chemical formulation, and this differs from species to species. (b) The chemical structures of three monomers of lignin: p-coumaryl alcohol, coniferyl alcohol, and sinapyl alcohol, respectively.
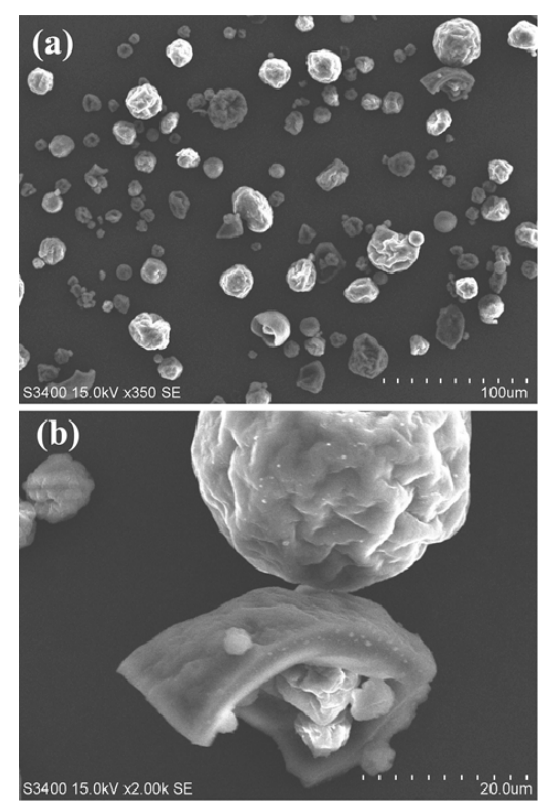

Figure 3. The SEM (scanning electron microscope) images of lignin particles obtained from an ethanol-water solution by evaporation of the solvent. (a) Most lignin particles are rough spheres with a diameter of tens to hundreds of micrometers. (b) A close view of larger lignin particles. Some of the lignin particles may be hollow spheres or pieces of broken spheres.

\subsection{Fabrication of GMC}

Two technical schemes are used in the preparation of GMC samples from lignin. Scheme 1 is a one-step procedure, in which the pyrolysis of lignin is performed in a tubular furnace under a nitrogen atmosphere with a temperature control program. The physical and chemical properties of the glassy carbon samples are controllably influenced by the heating procedure $[7,8]$. The temperature control 
program is carefully designed as follows. Period 1 is a melting process of the lignin powder, in which the temperature increases from room temperature to $180{ }^{\circ} \mathrm{C}$ with a ramp rate of $1^{\circ} \mathrm{C} \mathrm{min}{ }^{-1}$ under a flow of nitrogen, maintaining the temperature at $180{ }^{\circ} \mathrm{C}$ for $1 \mathrm{~h}$ for complete and uniform melting. Period 2 is a thermal pyrolysis process of lignin in the temperature range of $180{ }^{\circ} \mathrm{C}$ to $450{ }^{\circ} \mathrm{C}$ with a ramp rate of $1^{\circ} \mathrm{C} \mathrm{min}^{-1}$, in which the volatile organic molecules and water molecules escape with the nitrogen flow. Period 3 is the carbonization and graphitization of lignin at high temperature, in which the temperature increases from $450{ }^{\circ} \mathrm{C}$ to a chosen high temperature $\left(800{ }^{\circ} \mathrm{C}, 1000{ }^{\circ} \mathrm{C}\right.$, or $\left.1200{ }^{\circ} \mathrm{C}\right)$ at a ramp rate of $2^{\circ} \mathrm{C} \mathrm{min}^{-1}$ in a nitrogen atmosphere, maintaining the high temperature for $3 \mathrm{~h}$. Period 4 is an annealing process of glassy carbon in a nitrogen atmosphere. In this step, the temperature decreases from the chosen high temperature to $30{ }^{\circ} \mathrm{C}$ at a ramp-up rate of $5{ }^{\circ} \mathrm{C} \mathrm{min}-1$.

Scheme 2 is a two-step procedure that combines the hydrothermal carbonization (HTC) [50-53] with the pyrolysis of lignin. In the first step, $10 \mathrm{~g}$ lignin and $50 \mathrm{~g}$ deionized water are sealed in a $100 \mathrm{ml}$ HTC reactor, where an aquathermolysis reaction of lignin takes place at $240{ }^{\circ} \mathrm{C}$ and $100 \mathrm{mPa}$, the vapor pressure of water corresponding to that temperature. In the second step, the pyrolysis reaction of partially carbonized lignin is performed in a tubular furnace at a high temperature, as in Scheme 1. The experimental equipment of Scheme 1 and Scheme 2 are illustrated in Figure 4.

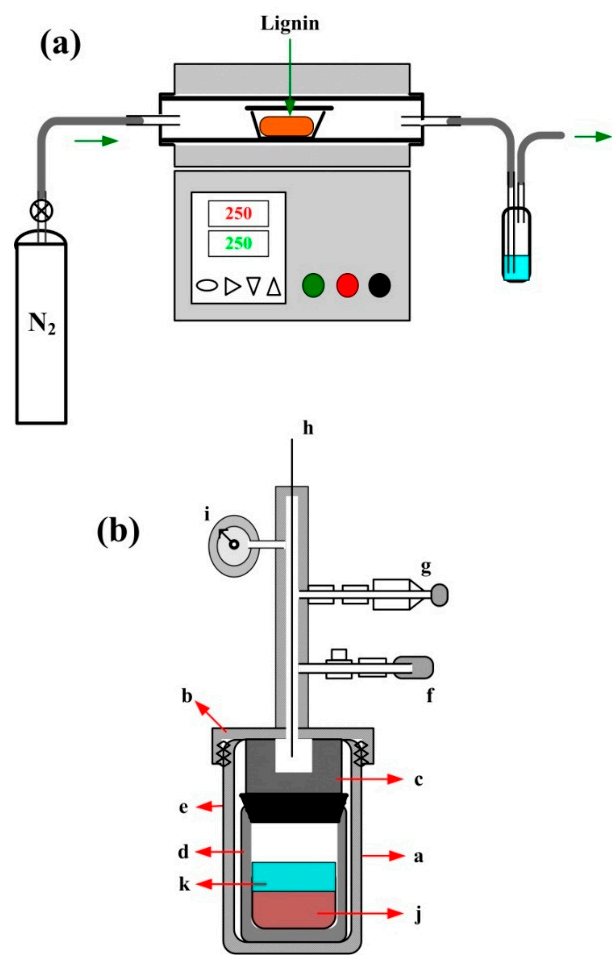

Figure 4. Two technical schemes used in the preparation of GMC samples. (a) The lignin pyrolysis procedure in a tubular furnace with a temperature control program under a nitrogen atmosphere and at atmospheric pressure. (b) The hydrothermal carbonization (HTC) procedure of lignin at $240{ }^{\circ} \mathrm{C}$ and the corresponding vapor pressure of water, approximately $100 \mathrm{mPa}$. (a: Cylinder; b: Cover; c: Block; d: Teflon cylinder; e: Teflon cover; f: Relief valve; g: Safety valve; h: Thermocouple; i: Pressure gage.)

\section{Results and Discussion}

In this section, the GMC samples prepared using the two technical schemes under different reaction conditions are characterized using SEM and high-resolution transmission electron microscope (HRTEM) images and spectra of FTIR, XRD, Raman, and XPS. The photographs of typical GMC samples prepared in this study are shown in Figure 5. 

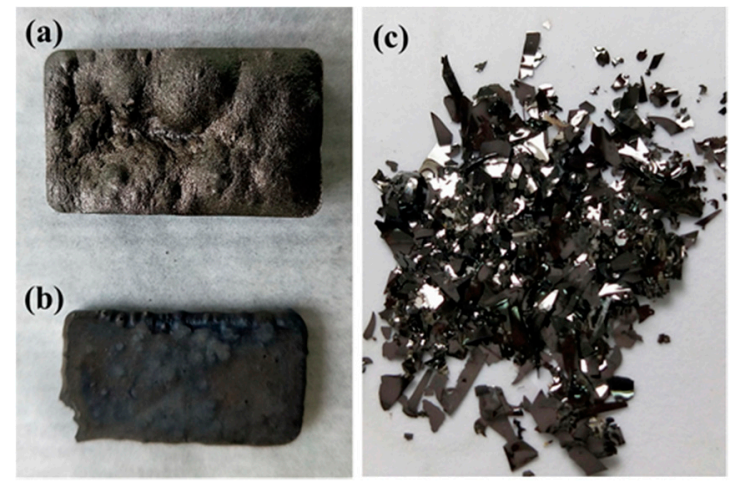

Figure 5. The photographs of GMC samples prepared in this study. (a) The GMC sample prepared at $800{ }^{\circ} \mathrm{C}$ in a tubular furnace. (b) The GMC sample prepared at $1200{ }^{\circ} \mathrm{C}$ in a tubular furnace. (c) The GMC sample prepared using an HTC-Pyr two-step technique at $240{ }^{\circ} \mathrm{C}$ and $800{ }^{\circ} \mathrm{C}$.

\subsection{GMC Samples Prepared Using Scheme 1}

The GMC samples, prepared using a pyrolysis procedure, are described and characterized as follows.

\subsubsection{SEM and TEM Images of GMC Samples}

The hard and rigid graphene microcrystal samples are ground into powders. The SEM images of glassy carbon powders, prepared using Scheme 1 at $800{ }^{\circ} \mathrm{C}, 1000{ }^{\circ} \mathrm{C}$ and $1200{ }^{\circ} \mathrm{C}$, are shown in Figure 6a-c, respectively. In Figure 6, the broken slags of GMC samples show sharp edges and curved faces, very similar to the powder of common glasses and ceramics. In the GMC sample prepared at $800{ }^{\circ} \mathrm{C}$, shown in Figure 6a, there are many holes. However, with the temperature increase, the GMC samples become more compact and uniform. The HRTEM (high-resolution transmission electron microscope) images of the GMC samples in Figure 7a,b clearly show the glassy-like microcrystal structures and the crystal fragments of the graphene sheets. In the GMC samples, most graphene fragments consist of three to five parallel graphene sheets at a size of 3 to $5 \mathrm{~nm}$.
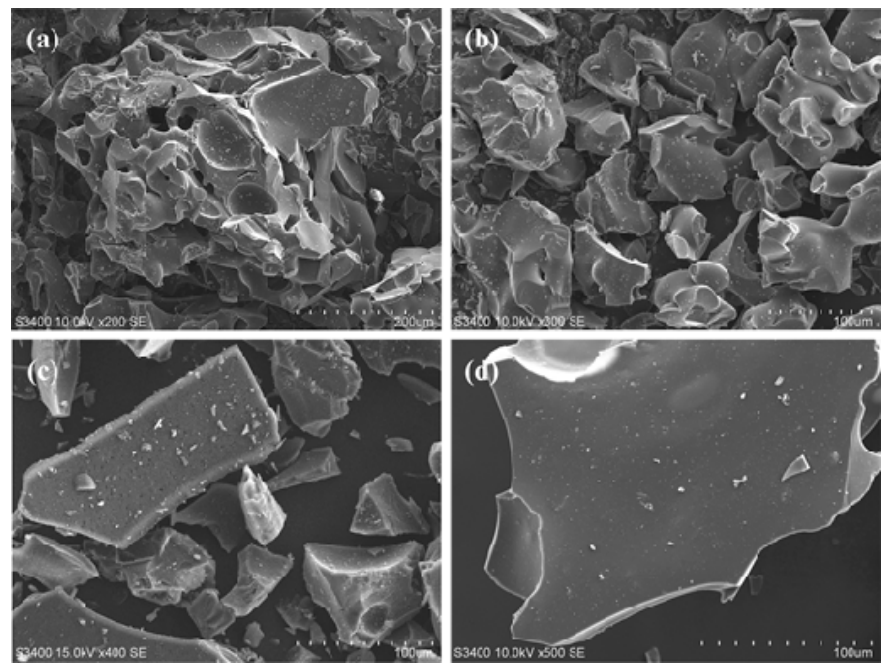

Figure 6. The SEM images of GMC samples. (a) GMC sample prepared in a tubular furnace at $800{ }^{\circ} \mathrm{C}$. (b) GMC sample prepared in a tubular furnace at $1000^{\circ} \mathrm{C}$. (c) GMC sample prepared in a tubular furnace at $1200^{\circ} \mathrm{C}$. (d) A close view of a GMC sample prepared in a tubular furnace at $1200{ }^{\circ} \mathrm{C}$. In the GMC sample, prepared at $800{ }^{\circ} \mathrm{C}$, there are more holes. However, with the temperature increase the GMC samples become more compact and uniform. 

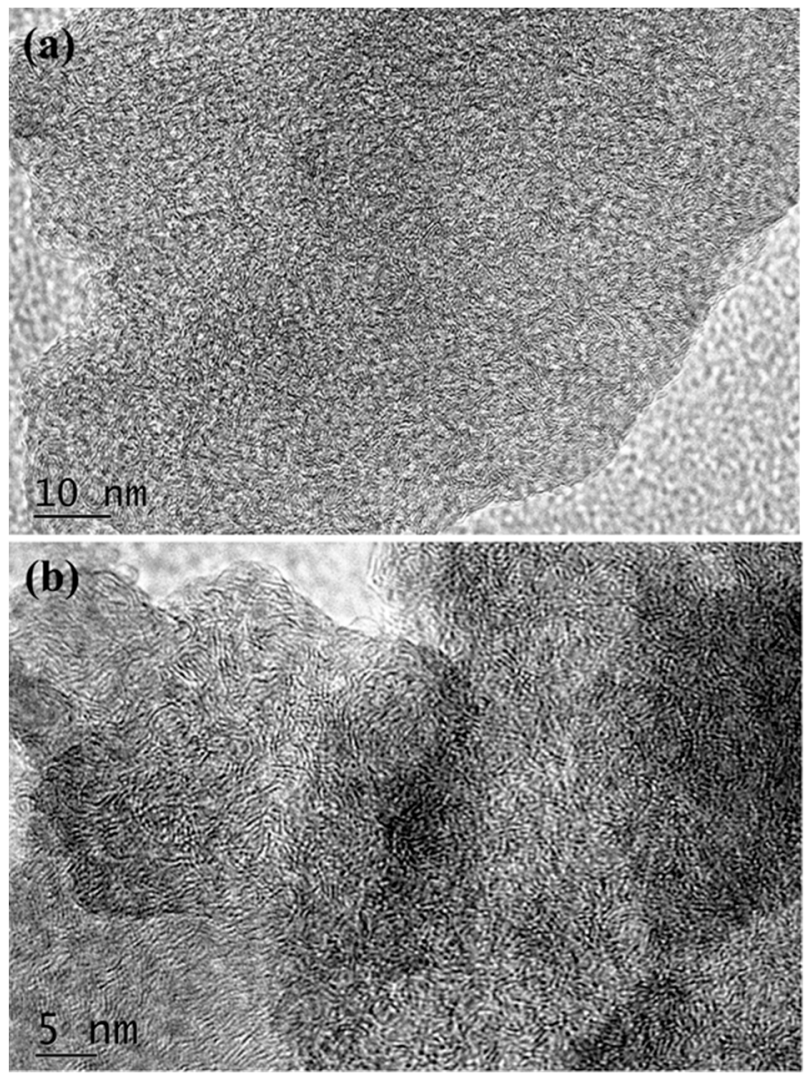

Figure 7. The HRTEM (high resolution transmission electron microscope) images of the GMC samples. (a) The TEM image of GMC sample at a resolution of $10 \mathrm{~nm}$. (b) The TEM image of a GMC sample at a resolution of $5 \mathrm{~nm}$. The TEM images clearly show the graphene sheets and the glassy-like microcrystals in the GMC samples. In GMC samples, most graphene fragments consist of 3 to 5 graphene sheets with dimensions of 3 to $5 \mathrm{~nm}$.

\subsubsection{FTIR Spectra of Lignin and GMC Sample}

For comparison, the FTIR spectra of the precursor lignin and the GMC sample prepared at $1000{ }^{\circ} \mathrm{C}$ are shown in Figure 8a,b, respectively. In Figure 8a, the two peak bands around $1400-1600 \mathrm{~cm}^{-1}$ and $1000-1200 \mathrm{~cm}^{-1}$ are the vibrations of aromatic skeletal bonds [54]. The two peak bands in the range 2950-3050 and 2850-2945 $\mathrm{cm}^{-1}$ correspond to the C-H bond stretching vibrations of $\mathrm{sp}^{2}$ and $\mathrm{sp}^{3}$ carbon atoms, respectively [29]. Based on the peak intensity analysis, the ratio of $\mathrm{sp}^{2}$ to $\mathrm{sp}^{3}$ carbon atoms in lignin is calculated to be 3.84 [29]. In contrast, all above peaks of $\mathrm{C}-\mathrm{H}$ bonds and aromatic bonds almost disappear in the FTIR spectrum of a GMC sample, indicating the full carbonization of the precursor lignin during the thermal pyrolyzation reaction.

\subsubsection{XRD Patterns of GMC Samples}

$\mathrm{X}$-ray diffraction $(\mathrm{XRD})$ is typically used to characterize the structure and layers of graphene materials [55,56]. The XRD patterns of GMC samples, prepared at $800^{\circ} \mathrm{C}, 1000^{\circ} \mathrm{C}$, and $1200^{\circ} \mathrm{C}$ are shown in Figure 9. The diffraction peak centered around $2 \theta=25^{\circ} \sim 26.5^{\circ}$ comes from the reflection of the 002 planes in the GMC samples. In Figure 9, with the temperature increase, the diffraction peak of the 002 plane moves from $25^{\circ}$ to $26.5^{\circ}$ and increases in intensity. The value of $26.5^{\circ}$ corresponds to the interlayer space, $0.34 \mathrm{~nm}$, in the graphene crystal, indicating superior graphitization of GMC samples under higher temperatures. In Figure 9, the XRD pattern of reduced graphene oxide (rGO), cited from Nanonics Imaging Ltd. (www.nanonics.co.il) is given in the inset to the figure. The XRD 
patterns of the GMC samples are highly similar to the XRD pattern of $\mathrm{rGO}$, indicating the presence of oxygen groups in the graphene sheets of the GMC samples.
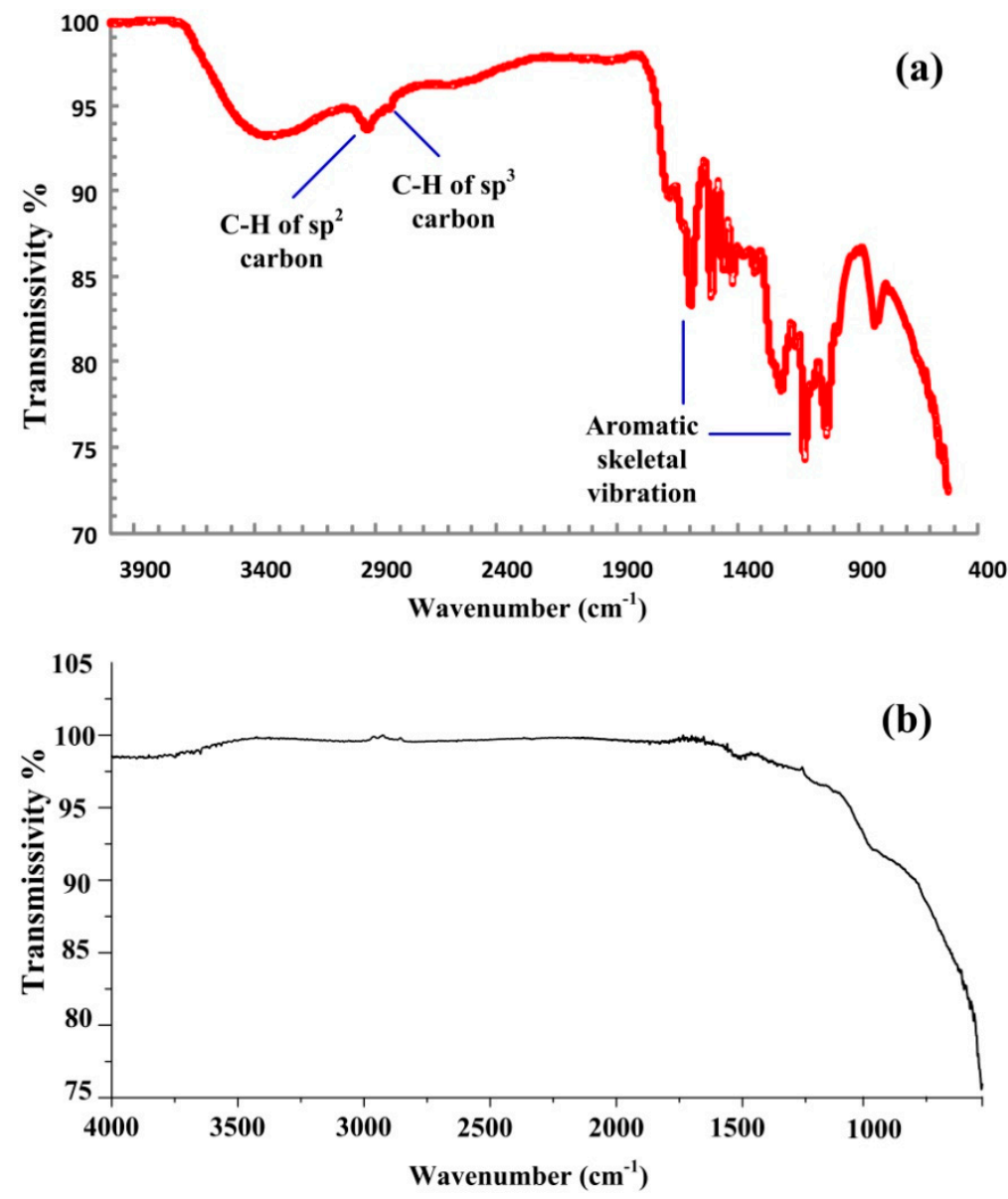

Figure 8. The FTIR spectra of lignin and a GMC sample. (a) The FTIR spectrum of lignin (red) isolated and purified from sugarcane bagasse. (b) The FTIR spectrum of a GMC sample prepared at $1000{ }^{\circ} \mathrm{C}$. The peaks of $\mathrm{C}-\mathrm{H}$ bonds and aromatic bonds almost disappear in the FTIR spectrum of the GMC sample, indicating the full carbonization of the precursor lignin during the thermal pyrolyzation reaction.

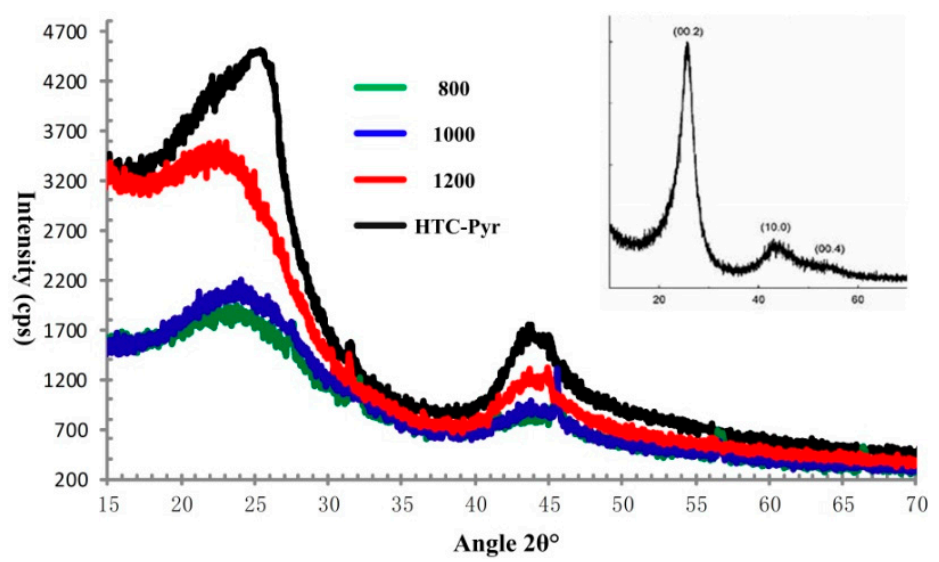

Figure 9. The XRD patterns of GMC samples, prepared at three temperatures: $800{ }^{\circ} \mathrm{C}$ (green), $1000{ }^{\circ} \mathrm{C}$ (blue), $1200{ }^{\circ} \mathrm{C}$ (red), and using an HTC-Pyr (black) technique. The XRD patterns of GMC samples are very close to the XRD pattern (inset) of reduced graphene oxide (rGO) (www.nanonics.co.il), indicating the presence of an oxygen group in the graphene sheets of the GMC samples. 


\subsubsection{Raman Spectra of GMC Samples}

A Raman spectrum is a useful tool for the characterization of graphene samples and related materials [57-59]. The Raman spectra of GMC samples prepared at three temperatures $\left(800{ }^{\circ} \mathrm{C}, 1000^{\circ} \mathrm{C}\right.$, $1200^{\circ} \mathrm{C}$ ) are shown in Figure 10, in which there is a high D band at $1339 \mathrm{~cm}^{-1}$, a relatively lower $\mathrm{G}$ band at $15,917 \mathrm{~cm}^{-1}$, and a flat $2 \mathrm{D}$ band at $2655 \mathrm{~cm}^{-1}$. Comparing the Raman shifts of the GMC samples in Figure 10, prepared under different temperatures, as the temperature increases the intensities of peaks D and G get higher. The spectrum on the upper right corner in Figure 10, is the typical Raman shift of reduced graphene oxide (rGO), cited from Nanonics Imaging Ltd. (www.nanonics.co.il). The Raman shifts of GMC samples are very similar to those of $\mathrm{rGO}$, indicating the existence of oxygen groups in graphene sheets of the GMC samples. However, the oxygen fraction in GMC samples is less than that in rGO.

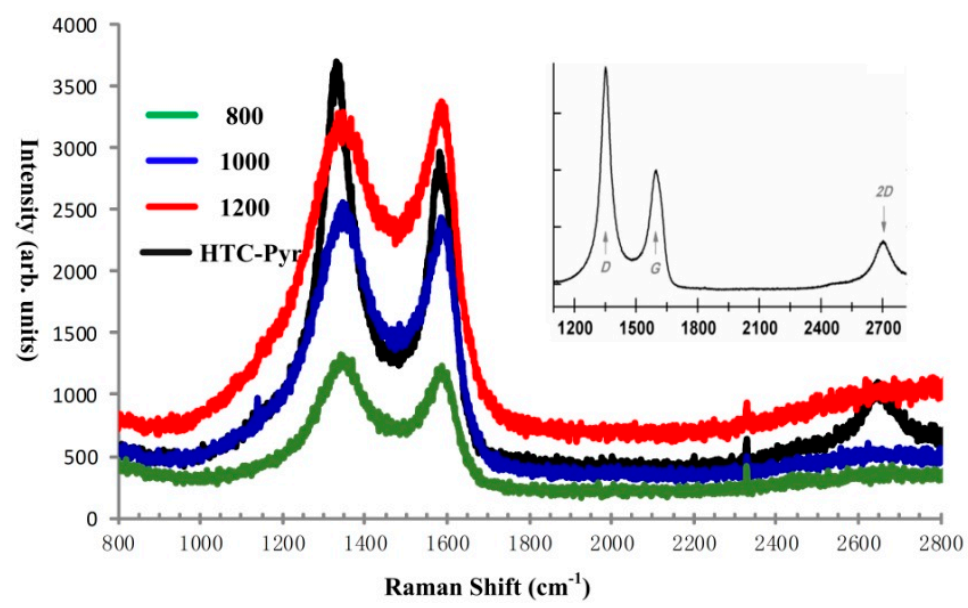

Figure 10. The Raman spectra of GMC samples prepared at four temperatures: $800{ }^{\circ} \mathrm{C}$ (green), $1000{ }^{\circ} \mathrm{C}$ (blue), $1200{ }^{\circ} \mathrm{C}$ (red), and using an HTC-Pyr (black) technique. The Raman spectra of GMC samples are very similar to the Raman spectrum (see inset) of rGO (www.nanonics.co.il), indicating the presence of graphene sheets in the GMC samples. However, the oxygen fraction in GMC samples is less than that in rGO.

\subsubsection{XPS Spectra of GMC Samples}

The XPS spectra [60-62] of GMC samples prepared at three temperatures $\left(800{ }^{\circ} \mathrm{C}, 1000{ }^{\circ} \mathrm{C}\right.$, and $1200^{\circ} \mathrm{C}$ ) are shown in Figure $11 \mathrm{a}-\mathrm{C}$, respectively, and the experimental data from XPS experiments are reported in Table 1 . In the XPS spectra, the carbon C1s profiles are separated into carbon $\mathrm{sp}^{2}$ peaks (red, centered at $284.4 \mathrm{eV}$ ) and carbon $\mathrm{sp}^{3}$ peaks (blue, centered at $285.2 \mathrm{eV}$ ) [63] using the XPS peak fitting program XPSPEAK 4.1 (http:/ /xpspeak.software.informer.com/4.1/). An interesting phenomenon was observed in which a temperature increase caused the $\mathrm{sp}^{3}$ peak (blue) to diminish, while the $\mathrm{sp}^{2}$ peak (red) increased in intensity, implying the graphitization of GMC sample increases with the elevation of temperature. In Table 1, the ratio of $\mathrm{sp}^{2}$ carbon atoms to $\mathrm{sp}^{3}$ carbon atoms is 8:1 in the GMC sample prepared at $1200{ }^{\circ} \mathrm{C}$. In the graphene microcrystal samples, oxygen is the main impurity. With the elevation of temperature, the fraction of oxygen decreases, while the fraction of carbon increases. When the temperature increases to $1200{ }^{\circ} \mathrm{C}$, the fraction of carbon reaches $93.27 \%$, while the fraction of oxygen decreases to $6.27 \%$. 
Table 1. The $\mathrm{sp}^{2}$ to $\mathrm{sp}^{3}$ ratio of carbon atoms and the elemental ratio in graphene microcrystal samples.

\begin{tabular}{cccccc}
\hline \multirow{2}{*}{ Temperature $\left({ }^{\circ} \mathbf{C}\right)$} & \multicolumn{2}{c}{ Valence Ratio (\%) } & \multicolumn{3}{c}{ Element (\%) } \\
\cline { 2 - 6 } & C-sp $^{\mathbf{2}}$ & C-sp & Carbon & Oxygen & Other \\
\hline 800 & 58.05 & 41.95 & 79.02 & 14.95 & 6.03 \\
1000 & 77.08 & 22.92 & 83.82 & 12.10 & 4.08 \\
1200 & 88.73 & 11.27 & 93.27 & 6.27 & 0.46 \\
HTC-Pyr & 80.83 & 19.17 & 88.56 & 8.45 & 2.99 \\
\hline
\end{tabular}
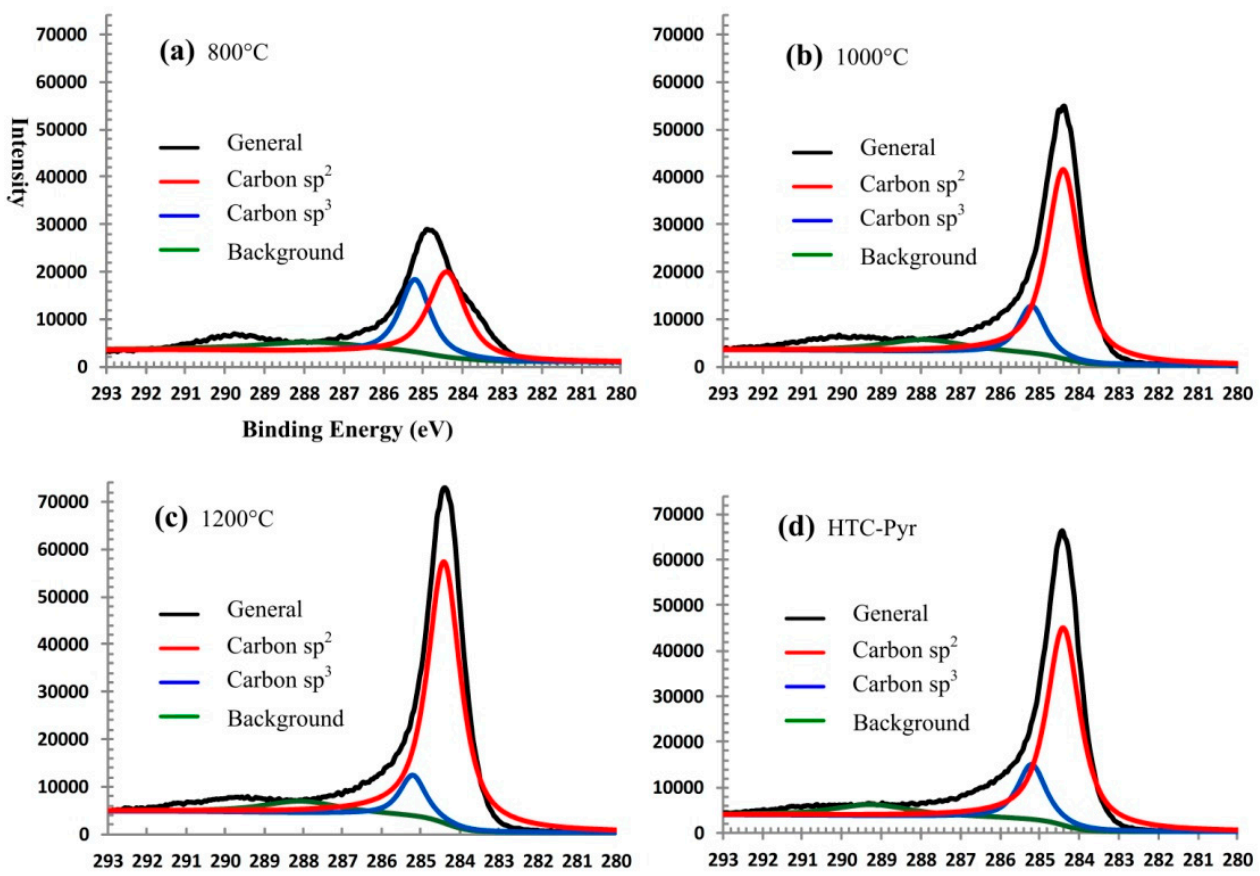

Figure 11. The XPS spectra of GMC samples prepared at three temperatures and using an HTC-Pyr technique. (a) XPS spectra of GMC samples prepared at $800{ }^{\circ} \mathrm{C}$. (b) XPS spectra of GMC samples prepared at $1000{ }^{\circ} \mathrm{C}$. (c) XPS spectra of GMC samples prepared at $120{ }^{\circ} \mathrm{C}$. (d) XPS spectra of GMC samples prepared using HTC-Pyr method. The carbon C1s profiles are separated into carbon $\mathrm{sp}^{2}$ peaks (red, centered at $284.4 \mathrm{eV}$ ) and carbon $\mathrm{sp}^{3}$ peaks (blue, centered at $285.2 \mathrm{eV}$ ) using the XPS peak-fitting program, XPSPEAK 4.1.

\subsection{GMC Sample Prepared from Scheme 2}

The GMC sample, prepared using technique Scheme 2 (HTC and Pyrolysis), is described and characterized in this section. The big difference between Scheme 1 and Scheme 2 is that in Scheme 1 each reaction was carried out under atmospheric pressure $(0.1 \mathrm{mPa})$, while in Scheme 2 the HTC reaction takes place under higher pressure, around $100 \mathrm{mPa}$, the vapor pressure of water at $240{ }^{\circ} \mathrm{C}$. However, in the HTC reaction, the temperature cannot be elevated too high for safety reasons. In the second step, the partially carbonized lignin is further graphitized in a tubular furnace at $800{ }^{\circ} \mathrm{C}$ in a nitrogen atmosphere. The photographs and spectra of XRD, Raman, and XPS of GMC samples prepared using Scheme 2 are shown in Figures 5 and 9-11, respectively, with those of GMC samples prepared using Scheme 1 for comparison. In Figure 5, the photograph of HTC-Pyr graphene microcrystals shows them to be shining and bright due to the flushing of water vapor at high pressure. In Figure 9, the XRD pattern (black) of HTC-Pyr glassy carbon is very close to that of reduced graphene oxide (rGO). In Figure 10, the Raman spectrum that is most similar to reduced graphene oxide (rGO) is that of HTC-Pyr GMC (black). In Figure 11, the ratio of $\mathrm{sp}^{2}$ carbon atoms to $\mathrm{sp}^{3}$ carbon atoms in HTC-Pyr graphene microcrystals is higher than that of the GMC sample prepared under $1000^{\circ} \mathrm{C}$. In Table 1 , 
the HTC-Pyr GMC possesses a higher fraction of carbon and a lower fraction of oxygen than the GMC sample prepared under $1000^{\circ} \mathrm{C}$.

\section{Conclusions}

Based on this study, some useful conclusions are summarized as follows. (1) Graphene microcrystal (GMC), a type of glassy carbon, is successfully fabricated from lignin, which consists of nanoscale graphene microcrystal fragments, chemically bonded by $\mathrm{sp}^{3}$ carbon atoms, forming a glass-like long-range disorder and short-range order microcrystal structure that is demonstrated by XRD, Raman, XPS, SEM, and HRTEM experiments. (2) Lignin, the second-largest sustainable biomass material in the natural world, is proven as a qualified and sustainable material for the manufacture of GMC. Lignin is a substitute for the traditional raw materials of glassy carbon, copolymer resins of phenol formaldehyde, and furfuryl alcohol-phenol. (3) The merit of the organosolv biorefinery technique is that the lignin is isolated and dissolved from lignocellulose, keeping its original chemical structure and with no other chemical elements introduced, unlike Kraft lignin and alkaline lignin. (4) The temperature and pressure have important impacts on the quality of GMC samples. With the elevation of temperature, the ratio of $\mathrm{sp}^{2}$ carbon atoms to $\mathrm{sp}^{3}$ carbon atoms and the component of carbon increase, while the component of oxygen decreases. The (HTC-pyrolysis) two-step technique could produce a better GMC sample at lower temperatures because of the high vapor pressure in the HTC reactor.

Currently, as-prepared GMC samples contain certain oxygen groups; the graphene fragments are similar to those in rGO. However, upon temperature elevation, the fraction of oxygen decreases. To obtain a better quality of GMC, more experiments must be performed.

Author Contributions: Q.-S.D., P.-D.T. and R.-B.H. conceived the theory and method and designed the experiments; F.-L.D., J.D., P.-D.T., and Y.-M.L. carried out the experiments; F.-L.D., N.-Z.X. and S.-Y.L. analyzed the samples; S.-Y.L. and N.-Z.X. prepared the materials and instruments. Q.-S.D., F.-L.D. and R.-B.H., wrote the article. All authors discussed the results and commented on the manuscript.

Funding: This work was supported by National Natural Science Foundation of China: 31360207 and 31370716, Guangxi President Research Funding: 16449-02.

Acknowledgments: This work was supported by a grant from the National Science Foundation of China (NSFC http: / / www.nsfc.gov.cn/) under the contract numbers 31360207 and 31370716, and was supported by Guangxi President Research Funding (No. 16449-02). We thank the National Supper Computing Center (NSCC www.nscctj.gov.cn) in Tianjin for the valuable help in the modeling calculations using a TH-1A super computer.

Conflicts of Interest: The authors declare no conflict of interest.

\section{References}

1. Cowlard, F.C.; Lewis, J.C. Vitreous carbon-A new form of carbon. J. Mater. Sci. 1967, 2, 507-512. [CrossRef]

2. Schueller, O.J.A.; Brittain, S.T.; Marzolin, C.; Whitesides, G.M. Fabrication and Characterization of Glassy Carbon MEMS. Chem. Mater. 1997, 9, 1399-1406. [CrossRef]

3. Schueller, O.J.A.; Brittain, S.T.; Whitesides, G.M. Fabrication of glassy carbon microstructures by pyrolysis of microfabricated polymeric precursors. Adv. Mater. 1997, 9, 477-480. [CrossRef]

4. $\quad$ Leung, T.Y.; Man, W.F.; Lim, P.K.; Chan, W.C.; Gaspari, F.; Zukotynski, S. Determination of the sp3/sp2 ratio of a-C:H by XPS and XAES. J. Non-Cryst. Solids 1999, 254, 156-160. [CrossRef]

5. Harris, P.J.F. Fullerene-related structure of commercial glassy carbons. Philos. Mag. 2003, 84, 3159-3167. [CrossRef]

6. Walsh, F.C.; Arenas, L.F.; de León, C.P.; Reade, G.W.; Whyte, I.; Mellor, B.G. The continued development of reticulated vitreous carbon as a versatile electrode material: Structure, properties and applications. Electrochim. Acta 2016, 215, 566-591. [CrossRef]

7. Stein, I.Y.; Kaiser, A.L.; Constable, A.J.; Acauan, L.; Wardle, B.L. Mesoscale evolution of non-graphitizing pyrolytic carbon in aligned carbon nanotube carbon matrix nanocomposites. J. Mater. Sci. 2017, 52, 13799-13811. [CrossRef] 
8. Stein, I.Y.; Constable, A.J.; Morales-Medina, N.; Acauan, L.; Wardle, B.L. Structure-mechanical property relations of non-graphitizing pyrolytic carbon synthesized at low temperatures. Carbon 2017, 117, 411-420. [CrossRef]

9. Craievich, A.F. On the structure of glassy carbon. Mater. Res. Bull. 1976, 11, 1249-1255. [CrossRef]

10. Hu, M.; He, J.; Zhao, Z.; Strobel, T.A.; Yu, D.; Hu, W.; Sun, H.; Liu, L.; Li, Z.; Ma, M.; et al. Compressed glassy carbon: An ultrastrong and elastic interpenetrating graphene network. Sci. Adv. 2017, 3, e1603213. [CrossRef] [PubMed]

11. Zhao, Z.; Wang, E.F.; Yan, H.; Kono, Y.; Wen, B.; Bai, L.; Shi, F.; Zhang, J.; Kenney-Benson, C.; Park, C.; et al. Nanoarchitectured materials composed of fullerene-like spheroids and disordered graphene layers with tunable mechanical properties. Nat. Commun. 2015, 6, 6212. [CrossRef] [PubMed]

12. Harris, P.J.F. New perspectives on the structure of graphitic carbons. Crit. Rev. Solid. State Mater. Sci. 2005, 30, 235-253. [CrossRef]

13. Wang, L.; Liu, H.; Li, W.; Yang, W.; Ding, Y.; Sinogeikin, S.V.; Meng, Y.; Liu, Z.; Zeng, X.C.; Mao, W.L. Long-range ordered carbon clusters: A crystalline material with amorphous building blocks. Science 2012, 337, 825-828. [CrossRef] [PubMed]

14. Brazhkin, V.V.; Solozhenko, V.L.; Bugakov, V.I.; Dub, S.N.; Kurakevych, O.O.; Kondrin, M.V.; Lyapin, A.G. Bulk nanostructured carbon phases prepared from C60: Approaching the 'ideal' hardness. J. Phys. Condens. Matter 2007, 19, 236209. [CrossRef]

15. Sharon, M.; Kumar, M.; Kichambare, P.D.; Neumann-Spallart, M. Electrochemical studies of kerosene-pyrolysedcarbon films. J. Appl. Electrochem. 1998, 28, 1399-1403. [CrossRef]

16. Angus, J.C.; Hayman, C.C. Low-pressure, metastable growth of diamond and "diamondlike" phases. Science 1988, 241, 913-921. [CrossRef] [PubMed]

17. Blank, V.D.; Buga, S.G.; Dubitsky, G.A.; Serebryanaya, N.R.; Popov, M.Y.; Sundqvist, B. High-pressure polymerized phases of C60. Carbon 1998, 36, 319-343. [CrossRef]

18. Schueller, O.J.A.; Brittain, S.T.; Whitesides, G.M. Fabrication of glassy carbon microstructures by soft lithography. Sens. Actuators A 1999, 72, 125-139. [CrossRef]

19. Zhao, X.-M.; Xia, Y.; Whitesides, G.M. Fabrication of Three-Dimensional Micro-Structures: Microtransfer Molding. Adv. Mater. 1996, 8, 837-840. [CrossRef]

20. Jenkins, G.M.; Kawamura, K. Polymeric Carbonss Carbon Fibre, Glass and Char; Cambridge University Press: Cambridge, UK, 1976

21. Lewis, J.C.; Redfern, B.; Cowlard, F.C. Vitreous carbon as a crucible material for semiconductors. Solid-State Electron. 1963, 6, 251-254. [CrossRef]

22. Stein, I.Y.; Wardle, B.L. Mechanics of aligned carbon nanotube polymer matrix nanocomposites simulated via stochastic three-dimensional morphology. Nanotechnology 2016, 27, 035701. [CrossRef] [PubMed]

23. Jurkiewicz, K.; Duber, S.; Fischerd, H.E.; Burian, A. Modelling of glass-like carbon structure and its experimental verification by neutron and X-ray Diffraction. J. Appl. Cryst. 2017, 50, 36-48. [CrossRef]

24. Cheng, S.J.; Chiu, H.Y.; Kumar, P.V.; Hsieh, K.Y.; Yang, J.W.; Lin, Y.R.; Shen, Y.C.; Chen, G.Y. Simultaneous drug delivery and cellular imaging using graphene oxide. Biomater. Sci. 2018, 6, 813-819. [CrossRef] [PubMed]

25. Fei, F.; Cseri, L.; Szekely, G.; Blanford, C.F. Robust Covalently Cross-linked Polybenzimidazole/Graphene Oxide Membranes for High-Flux Organic Solvent Nanofiltration. ACS Appl. Mater. Interfaces 2018, 10, 16140-16147. [CrossRef] [PubMed]

26. Ryan, A.J.; Kearney, C.J.; Shen, N.; Khan, U.; Kelly, A.G.; Probst, C.; Brauchle, E.; Biccai, S.; Garciarena, C.D.; Vega-Mayoral, V.; et al. Electroconductive Biohybrid Collagen/Pristine Graphene Composite Biomaterials with Enhanced Biological Activity. Adv. Mater. 2018, 30, e1706442. [CrossRef] [PubMed]

27. Razali, M.; Kim, J.F.; Attfield, M.; Budd, P.M.; Drioli, E.; Lee, Y.M.; Szekely, G. Sustainable wastewater treatment and recycling in membrane manufacturing. Green Chem. 2015, 17, 5196-5205. [CrossRef]

28. Rahnasto-Rilla, M.; Tyni, J.; Huovinen, M.; Jarho, E.; Kulikowicz, T.; Ravichandran, S.; Bohr, V.A.; Ferrucci, L.; Lahtela-Kakkonen, M.; Moaddel, R. Natural polyphenols as sirtuin 6 modulators. Sci. Rep. 2018, 8, 43. [CrossRef] [PubMed]

29. Mukhopadhyay, K.; Sharon, M. Glassy carbon from camphor-A natural source. Mater. Chem. Phys. 1997, 49, 105-109. [CrossRef] 
30. Jenkins, G.; Grigso, C.J. The fabrication of artifacts out of glassy carbon and carbon-fiber-reinforced carbon for biomedical applications. J. Biomed. Mater. Res. 1979, 13, 371-394. [CrossRef] [PubMed]

31. Mora, C. The projected timing of climate departure from recent variability. Nature 2013, 502, $183-187$. [CrossRef] [PubMed]

32. Canadell, J.G.; Le Quere, C.; Raupach, M.R.; Field, C.B.; Buitenhuis, E.T.; Ciais, P.; Conway, T.J.; Gillett, N.P.; Houghton, R.A.; Marland, G. Contributions to accelerating atmospheric CO2 growth from economic activity, carbon intensity, and efficiency of natural sinks. Proc. Natl. Acad. Sci. USA 2007, 104, 18866-18870. [CrossRef] [PubMed]

33. Dell, R.M.; Rand, D.A.J. Energy storage-A key technology for global energy sustainability. J. Power Sources 2001, 100, 2-17. [CrossRef]

34. Martin, M.A. First generation biofuels compete. New Biotechnol. 2010, 27, 596-608. [CrossRef] [PubMed]

35. Kuhad, R.C.; Gupta, R.; Khasa, Y.P.; Singh, A.; Zhang, Y.H.P. Bioethanol production from pentose sugars: Current status and future prospects. Renew. Sustain. Energy Rev. 2011, 15, 4950-4962. [CrossRef]

36. Yaman, S. Pyrolysis of biomass to produce fuels and chemical feedstocks. Energy Convers. Manag. 2004, 45, 651-671. [CrossRef]

37. Song, S.; Ma, F.; Wu, G.; Ma, D.; Geng, W.; Wan, J. Facile self-templating large scale preparation of biomass-derived 3D hierarchical porous carbon for advanced supercapacitors. J. Mater. Chem. A 2015, 3, 18154. [CrossRef]

38. Le Van, K.; Luong, T.T.T. Activated carbon derived from rice husk by $\mathrm{NaOH}$ activation and its application in supercapacitor. Prog. Nat. Sci. Mater. Int. 2014, 24, 191. [CrossRef]

39. Liu, F.; Chen, Y.; Gao, J. Preparation and Characterization of Biobased Graphene from Kraft Lignin. BioResources 2017, 12, 6545-6557. [CrossRef]

40. Fujita, J.-I.; Ueki, R.; Miyazawa, Y.; Ichihashi, T. Graphitization at interface between amorphous carbon and liquid gallium for fabricating large area graphene sheets. J. Vacuum Sci. Technol. B Nanotechnol. Microelectron. 2009, 27, 3063-3066. [CrossRef]

41. Arthur, F.S.C.; Ragauskas, J. Review of current and future softwood kraft lignin process chemistry. Ind. Crops Prod. 2004, 20, 131-141.

42. Szczerbowski, D.; Pitarelo, A.P.; Filho, A.Z.; Ramos, L.P. Sugarcane biomass for biorefineries: Comparative composition of carbohydrate and non-carbohydrate components of bagasse and straw. Carbohydr. Polym. 2014, 114, 95-101. [CrossRef] [PubMed]

43. Faix, O.; Grunwald, C.; Beinhoff, O. Determination of phenolic hydroxyl group content of milled wood lignins (MWL's) from different botanical origins using selective aminolysis, FTIR, 1H-NMR, and UV spectroscopy. Holzforschung 1992, 46, 425-432. [CrossRef]

44. Alekhina, M.; Ershova, O.; Ebert, A.; Heikkinen, S.; Sixta, H. Softwood kraft lignin for value-added applications: Fractionation and structural characterization. Ind. Crops Prod. 2015, 66, 220-228. [CrossRef]

45. Vanholme, R.; Morreel, K.; Ralph, J.; Boerjan, W. Lignin engineering. Curr. Opin. Plant Biol. 2008, 11, 1-8. [CrossRef] [PubMed]

46. Luckeneder, P.; Gavino, J.; Kuchernig, R.; Petutschnigg, A.; Tondi, G. Sustainable Phenolic Fractions as Basis for Furfuryl Alcohol-Based Co-Polymers and Their Use as Wood Adhesives. Polymers 2016, 8, 396. [CrossRef]

47. Guilherme, A.A.; Dantas, P.V.F.; Santos, E.S.; Fernandes, F.A.N.; Macedo, G.R. Evaluation of composition, characterization and enzymatic hydrolysis of pretreated sugarcane bagasse. Braz. J. Chem. Eng. 2015, 32, 23-33. [CrossRef]

48. Harris, P.J.F. Structure of non-graphitising carbons. Int. Mater. Rev. 1997, 42, 206-217. [CrossRef]

49. Klapiszewski, L.; Jamrozik, A.; Strzemiecka, B.; Matykiewicz, D.; Voelkel, A.; Jesionowski, T. Activation of Magnesium Lignosulfonate and Kraft Lignin: Influence on the Properties of Phenolic Resin-Based Composites for Potential Applications in Abrasive Materials. Int. J. Mol. Sci. 2017, 18, 1224. [CrossRef] [PubMed]

50. Kim, D.; Yoshikawa, K.; Park, K.Y. Characteristics of Biochar Obtained by Hydrothermal Carbonization of Cellulose for Renewable Energy. Energies 2015, 8, 14040-14048. [CrossRef]

51. Kim, D.; Lee, K.; Park, K. Hydrothermal carbonization of anaerobically digested sludge for solid fuel production and energy recovery. Fuel 2014, 130, 120-125. [CrossRef] 
52. Libra, J.A.; Ro, K.S.; Kammann, C.; Funke, A.; Berge, N.D.; Neubauer, Y.; Titirici, M.-M.; Fuhner, C.; Bens, O.; Kern, J.; et al. Hydrothermal carbonization of biomass residuals: A comparative review of the chemistry, processes and applications of wet and dry pyrolysis. Biofuels 2011, 2, 71-106. [CrossRef]

53. Manara, P.; Zabaniotou, A. Towards sewage sludge based biofuels via thermochemical conversion-A review. Renew. Sustain. Energy Rev. 2011, 16, 2566-2582. [CrossRef]

54. Ucar, G.; Meier, D.; Faix, O.; Wegener, G. Analytical pyrolysis and FTIR spectroscopy of fossil sequoiaden-dron giganteum (Lindl.) wood and MWLs isolated hereof. Eur. J. Wood Wood Prod. 2005, 63, 57-63. [CrossRef]

55. Blanton, T.N.; Majumdar, D. X-ray diffraction characterization of polymer intercalated graphite oxide. Powd. Diff. 2012, 27, 104-107. [CrossRef]

56. Ruammaitree, A.; Nakahara, H.; Akimoto, K.; Soda, K.; Saito, Y. Determination of non-uniform graphene thickness on SiC ( $\begin{aligned} & 0 \\ & 0\end{aligned} 0$ 1) by X-ray diffraction. Appl. Surf. Sci. 2013, 282, 297-301. [CrossRef]

57. Malard, L.M.; Pimenta, M.A.; Dresselhaus, G.; Dresselhaus, M.S. Raman spectroscopy in graphene. Phys. Rep. 2009, 473, 51-87. [CrossRef]

58. Ni, Z.; Wang, Y.; Yu, T.; Shen, Z. Raman Spectroscopy and Imaging of Graphene. Nano Res. B 2008, 1, $273-291$. [CrossRef]

59. Casiraghi, C.; Hartschuh, A.; Qian, H.; Piscanec, S.; Georgi, C.; Fasoli, A.; Novoselov, K.S.; Basko, D.M.; Ferrari, A.C. Raman spectroscopy of graphenes edges. Nano Lett. 2009, 9, 1433-1441. [CrossRef] [PubMed]

60. Hüfner, S. Photoelectron Spectroscopy: Principles and Applications; Springer: Berlin/Heidelberg, Germany, 1995.

61. Ray, S.; Shard, A.G. Quantitative Analysis of Adsorbed Proteins by X-ray Photoelectron Spectroscopy. Anal. Chem. 2011, 83, 8659-8666. [CrossRef] [PubMed]

62. Crist, B.V. Handbook of the Elements and Native Oxides (PDF); XPS International, Inc.: Marlborough, MA, USA, 2012.

63. Crist, B.V. A review of XPS data-banks. XPS Rep. 2007, 1, 1-52.

(C) 2018 by the authors. Licensee MDPI, Basel, Switzerland. This article is an open access article distributed under the terms and conditions of the Creative Commons Attribution (CC BY) license (http://creativecommons.org/licenses/by/4.0/). 